\title{
Life Satisfaction and Life Orientation as predictors of Psychological Well Being
}

\author{
Sudha Rathore ${ }^{1}$, Arun Kumar ${ }^{2}$, Akansha Gautam ${ }^{3}$
}

\section{ABSTRACT}

The objective of the study was to find the impact of Life Satisfaction and Life Orientation on Psychological wellbeing of Doctors working at SMS Medical College and Jaipur Dental College. The sample for the study consisted of 112 Doctors aged between 32 to 55 years (Male=60 \& Female=52). Scale of Life Satisfaction Test, Revised Life Orientation Test and Bradburn Scale of Psychological Well-Being were administered on the participants. Results showed that life orientation and life satisfaction was the significant predictors of Psychological well being among Doctors. Therefore the immediate implication of this study was to ensure that prevailing working environment should enhance positive orientation towards ones living and thus in turn enhance life satisfaction for their betterment.

Keywords: Life Orientation, Life Satisfaction, Psychological Wellbeing.

"A doctor must work eighteen hours a day and seven days a week, if you cannot console yourself to this, get out of the profession."

\section{- Martin H Fischer}

Medicine is a rewarding carrier and being a doctor involves a lifetime of learning. Doctors find tself satisfying to help improve or save the lives of others. Getting respect for their work and contribution in community is yet another benefit of doctors. They do have a sense of personal and financial satisfaction which may include research and training opportunities and freedom to provide quality healthcare. While being a doctor definitely has its advantages, the profession proves challenging as well. Doctors often cite long training periods in medical school. Time remains an issue even after earning a medical degree, since physicians often work long hours and don't have much time to spend with family, relatives and friends. For a doctor saving life can be rewarding but the responsibility that comes with being a doctor can be stressful, such as making a mistake losing a patient or fearing a loss of one. It has been largely seen in several researches that maintaining work-life balance often gets difficult in medical profession and stress was the most unfortunate outcome..

\footnotetext{
${ }^{1}$ Assistant Professor, G.D. Goenka University

2 JRF, DIPR, DRDO (Delhi)

${ }^{3}$ Scientist 'C', DIPR, DRDO (Delhi)

*Corresponding Author

(C) 2015 I S Rathore, A Kumar, A Gautam; licensee IJIP. This is an Open Access Research distributed under the terms of the Creative Commons Attribution License (http://creativecommons.org/licenses/by/2.0), which permits unrestricted use, distribution, and reproduction in any Medium, provided the original work is properly cited.
} 
As it has been rightly said by Dr Karen Sibert's that if having work life is important to you, tham don't become a doctor, in a controversial New York Times. As a doctor they work for nonstop 812 hours, constantly interrupted, remains in their basis sense of awareness all the time and patients also demands their constant empathy. They are saturated with information at times and need to make rapid decision without adequate information and if any error occurred the human, professional and financial consequences can be disastrous. Doctors deal with a lot of physical strain, particularly while dealing with difficult patient. There stresses may range from death of a child to terrible diagnoses. Doctors need to learn an unnatural skill of professional detachment. This may be useful and necessary but it may be maladaptive if it also stay infront of family, relatives or loved ones. Dealing with all the emotional stress, repression and optimizing emotions even the positive one they have a different life orientation as compared to the professionals working in other field. They have to deal with a lot of psychological stress which has an adverse effect on their work assets of life.

Thus, this study is taken up to investigate the impact of Life Satisfaction and Life Orientation on Psychological wellbeing among doctors. To fulfil the above objective it was hypothesized that all the variables of the study will have significant positive correlation between them. Secondly it was also hypothesized that life satisfaction and life orientation will be significant predictors of psychological well being.

\section{Optimism}

Optimism is a generalized expectancy, that one will experience good outcomes in life, attitude or worldview to interpret past or present events in a positive manner (Carver, Scheier, \& Segerstrom, 2010). This expectancy that differs from person to person is a predictor of behavior (Scheier \& Carver, 1992) and leads to perseverance and striving toward goal-directed behavior (Carver et al., 2010).

\section{Psychological Well Being}

Psychological well-being is a broad concept. A wide variety of terms, concepts and measures are used by different researchers (Dattilo, Dattilo, Samdahe \& Kleiber, 1994) for describing or studying the phenomena of psychological well-being. PWB is the continuous process of experiencing and the realization of a person's true potential, personal growth, and purpose in life (Ryff, 1989; Ryff \& Singer, 1998). It is a proactive and intentional aspect of one's life comprising of autonomy, self-acceptance and mastery, and personality characteristics such as curiosity, integrity, spirituality, and forgiveness (Ryan \& Deci, 2000;Seligman, 2002, 2011).

\section{Life Satisfaction}

Life satisfaction is the way a person evaluates his or her life and how he or she feels about where it is going in the future. It is a measure of well-being and may be assessed in terms of mood, satisfaction with relations with others and with achieved goals, self-concepts, and self-perceived ability to cope with daily life. It is having a favourable attitude of one's life as a whole rather 
than an assessment of current feelings. Life satisfaction has been measured in relation to economic standing, amount of education, experiences, and residence, as well as many other topics (Diener, Emmons, Larsen, Griffin, 1985).

\section{METHOD}

\section{Sample and Procedure}

The correlation research design was used to investigate the relationship between life orientation, life satisfaction and psychological well- being among doctors. The sample for the study consisted of 112 Doctors aged between 32 to 55 years (Male=60 \& Female=52). Respondents were selected from two medical colleges located in Jaipur. Only those doctors were selected who had spent at least three years in this profession. The participants were in the age range of 32 to 55 years with the mean age of 39.14. All participants received information sheets stating the purpose of the study and signed consent forms prior to participating in the study. Help was provided to the participants in case they found any of the items difficult to comprehend. The Questionnaires were administered to the participants. Results were obtained and analyzed by SPSS 21 and used in the current study.

The researcher utilized three sets of questionnaire for data collection.

\section{Satisfaction with Life Scale (Diener, Emmons, Larsen \& Griffin, 1985)}

It is a self report measure consists of 5 items designed to measure global cognitive judgements of one's life satisfaction (not a measure of either positive or negative effect). Participants indicate how they agree or disagree with each of the 5 items using a 7-point scale that ranges from 7strongly agree to 1 strongly disagree. Internal consistency reliability found to significant (.78).

\section{Life Orientation Test- Revised (Scheier, Carver \& Bridges, 1994)}

It is a common measure of optimism. It consists of 10 items which measures optimism v/ pessimism. Of the 10 items, 3 items measures optimism, 3 items measures pessimism and 4 items serve as fillers. Respondent rate each items on a 4-point scale: $0=$ strongly disagree, 1=disagree, 2=neutral, 3=Agree \& 4=Strongly agree. Test-retest reliability was good (ICC=.72) and internal consistency was also quite satisfactory $(\alpha=.69)$ (Hirsch, Britton \& Conner, 2010).

\section{Bradburn Scale of Psychological Well Being (Bradburn, 1969)}

This scale is also known as Affect Balance Scale. It's a self report measure. The scale is made up of two components: the positive affect and the negative affect component. Each component has 5 items. The scale asks participants if, in the past few weeks, they have felt certain emotions. The participants answer "yes" or "no" to each question. The "no" score 8is subtracted from the "yes" score to create a positive/negative affect difference scale. 


\section{RESULTS}

Table. 1 Correlation among Life Satisfaction, Life Orientation and Psychological Well Being $(N=112)$

\begin{tabular}{|l|l|l|l|}
\hline Measures & $\begin{array}{l}\text { Life } \\
\text { Satisfaction }\end{array}$ & $\begin{array}{l}\text { Life } \\
\text { Orientation }\end{array}$ & $\begin{array}{l}\text { Psychological } \\
\text { Well Being }\end{array}$ \\
\hline Life Satisfaction & 1 & $.193^{*}$ & $.324^{* *}$ \\
\hline Life Orientation & & 1 & $.428^{\text {** }}$ \\
\hline Psychological Well Being & & & 1 \\
\hline Mean & 27.61 & 16.00 & 2.32 \\
\hline SD & 4.42 & 3.25 & 1.40 \\
\hline
\end{tabular}

**significant at 0.01 level.

*significant at 0.05 level.

Pearson's coefficient of correlation was computed to measure the relationship between life satisfaction, life orientation and psychological wellbeing. Results showed that life satisfaction had significantly positive correlation with life orientation $(r=-.193, p<0.05)$ and psychological wellbeing ( $r=-.324, \mathrm{p}<0.01$ ). Similarly life orientation had significant moderate level positive correlation with psychological wellbeing $(r=-.428, p<0.01)$

Means and SDs of scores on life satisfaction ( $M=27.61, S D=4.42)$ life orientation ( $M=16$, SD $=3.25$ ) and psychological wellbeing $(\mathrm{M}=2.32, \mathrm{SD}=1.40)$ are also presented in Table 1.

Table. 2. Multiple regression analysis predicting psychological wellbeing from Life orientation and life satisfaction $(N=112)$.

\begin{tabular}{|l|l|l|l|l|l|l|}
\hline Predictors & $\boldsymbol{\beta}$ & $\mathbf{R}$ & $\mathbf{R}$ & $\begin{array}{l}\text { Adjusted R } \\
\text { Square }\end{array}$ & $\begin{array}{l}\mathbf{R} \\
\text { Square } \\
\text { Change }\end{array}$ & F \\
\hline Life Orientation & .163 & .494 & .244 & .230 & .183 & $17.582 * *$ \\
\cline { 1 - 6 } & .079 & & & .061 & \\
\hline
\end{tabular}

**significant at 0.01 level.

Table 2 showed that stepwise regression revealed a significant model for the value of psychological wellbeing, $\mathrm{F}=17.582, \mathrm{p}=.000$, which explained $23 \%$ of the variance (Adjusted $\left.\mathrm{R}^{2}=.23\right)$. In the model, life orientation $(\beta=.163)$ and life satisfaction $(\beta=.079)$ emerged as the predictors for psychological wellbeing. 


\section{DISCUSSION}

The preliminary findings of this study revealed that there is a significant positive correlation between the variables of the study viz. Life satisfaction, life orientation (optimism) and psychological well being among doctors.

Table 2 show the result of stepwise regression analysis used to find out whether the independent variables of the study viz. life satisfaction and life orientation predicts psychological well being among doctors. A glance at the Table 2 reveals that all the variables put together contribute 24.4\% variance in predicting Psychological well being which is found to be significant at 0.1 level $(\mathrm{F}=17.582)$. Individually life orientation $(18.3 \%)$ contributes more variance than life satisfaction (6.1\%) in predicting psychological well being.

\section{Life Satisfaction}

There is a positive significant correlation between life Satisfaction and Psychological wellbeing. These finding are supported by previous research for instance, Arafa, Nazel, Ibrahim and Attia (2003) on nurses reported that Life Satisfaction and Social support are the significant predictors of Psychological well being. Another study be Demirbtir, Helvaci, Yilmaz, Gul, Senol \& Bilgel (2013) also found that depression and life satisfaction has a significant and positive relationship. Lyubomirsky, King \& Diener (2005) found that positive affect may be the cause of many desirable characteristics, resources and successes correlated with happiness. Diener, Sandvik \& Pavot (1991) have also observed that life satisfaction is a function of the preponderance of the positive affect in daily life.

In another study by Lert, Chastang, \& Castano (2001) it has been reported that stress derived from patients suffering was not related to any psychological outcomes. Work overload and stress derived from social relationships at work are the main predictors of psychological distress, emotional exhaustion and depersonalization, while the moderator effect of satisfaction is weak.

Life satisfaction is not a single entity rather it is a multidimensional approach. Many areas discussed by different researchers under this broad phenomena, like satisfaction with family life, satisfaction with professional life, satisfaction with job and satisfaction with peers (Gilman \& Huebner, 2003). Huebner (2004) discussed the predictors of life satisfaction. He claimed that healthy inter and intrapersonal relationships, less physical complaints, positive psychological health is strongly associated with high level of life satisfaction. He also asserted that poor life satisfaction is linked with depression, poor self-concept, adjustment problems, alcohol use and different other psychopathologies.

\section{Life Orientation (optimism)}

There is a positive significant relationship between life orientation and Psychological well being among doctors. This study also supported by Souri \& Hejazi (2014) who reported that optimism played a minor mediation role between resilience and psychological well being and also helps in 
contributing significant variance in predicting psychological well being. Mittal \& Mathur (2011) posited that professional scored average and high on the scale of learned optimism and life satisfaction which in turn resulted into psychological well being. Thus creating an environment to remain healthy, emotive and productive one has to be optimistic for future success.

It has been found from the results that optimism is the second contributing factor of psychological well-being. A substantial body of researches indicated that optimism is associated with psychological and physical well-being. Optimism helped people to cope up with stress and reduce risk of illness (Horowitz et al., 1988). Similarly Scheier and Carver (1992) found that optimism continued to be an important predictor of subjective well-being. People with an upbeat, optimistic explanatory style tend to enjoy good health (Peterson and Bossio, 1991). Maintaining a positive outlook towards life and an optimistic approach to future are the qualities that add to well-being (Dubey and Agarwal, 2004). The concept of future orientation is related to individual's hopes and fears, his/her expectations, aspirations, plans and striving for goals. Future orientation has motivational and cognitive components. It not only influences the behavior of an individual but is also influenced by the events in one's life such as prolonged deprivation (Agarwal, Tripathi \& Srivastava, 1983). Researchers in occupational health and health psychology have demonstrated that well-being is impacted by hope (Snyder, Lehman, Kluck \& Monsson, 2006), self-efficacy (Axtell, Hallman, Waterson, Harrington \& Unsworth, 2000 and Meier, Semmer, Elfering \& Jacobshagen, 2008), and optimism (Carver, Smith, Antoni, Petronic, Weiss \& Derhagopian, 2005).

\section{CONCLUSION}

Thus it will be important to determine the extent to which psychological well-being can be enhanced by key positive forces like Life satisfaction and Life orientation. Positive emotions, feelings and a positive mental attitude can improve the quality of people's lives and heal their illness and stresses. On the other hand, negative emotions and feelings add toxins to the organism. Irrational beliefs about life events generate irrational emotions, whereas rational beliefs result in rational emotions. So if people learn how to recognize and reorganize their irrational beliefs and replace them with healthy ones, they will feel better. So doctors need to develop a positive attitude towards life in order to maintain life satisfaction and to incorporate optimism to live a happy and healthy life which in turn enhances psychological well being.

\section{REFRENCES}

Agarwal, A., Tripathi, K.K., \& Srivastava, M. (1983). Psychological implications of time perspective. International Journal of Psychology, 18, 367-380.

Arafa, M.A., Nazel, M.W., Ibrahim, N.K., \& Attia, A. (2003). Predictors of psychological wellbeing of nurses in Alexandria, Egypt. Int J Nurs Pract. 9(5), 313-20.

Axtell, C., Holman, D., Wall, T., Waterson, P., Harrington, E., \& Unsworth, K. (2000). Shopfloor innovation: Facilitating the suggestion and implementation of ideas. Journal of Occupational and Organizational Psychology, 73, 265-285.

Bradburn N.M.(1969). The structure of psychological well-being. Chicago: Aldine. 
Carver C. S., Scheier M. F., \& Segerstrom S. C. (2010). Optimism. Clinical Psychology Review, 30, 879-889.doi:10.1016/j.cpr.2010.01.006

Carver, C. S., Smith, R. G., Antoni, M. H., Petronis, V. M., Weiss, S., \& Derhagopian, R. P. (2005). Optimistic personality and psychosocial well-being during treatment predict psychosocial well-being among long-term survivors of breast cancer. Health Psychology, 24, 508-516.

Dattilo, J., Dattilo, A. M., Samdahl, D. M., \& Kleiber, D. A. (1994). Leisure orientations and self-esteem in women with low incomes who are overweight. Journal of Leisure Research, 26, 23-38.

Demirbatir, E., Helvaci, A., Yilmaz, N., Gul, G,, Senol, A., \& Bilgel, N. (2013). The Psychological Well-Being, Happiness and Life Satisfaction of Music Students. Psychology, 4, 16-24.

Diener, E., Emmons, R. A., Larsen, R. J., \& Griffin, S. (1985). The Satisfaction with Life Scale. Journal of Personality Assessment, 49, 71-75.

Diener, E., Emmons, R. A., Larsen, R. J., Griffin, S. (1985). The satisfaction with life scale. Journal of Personality Assessment, 49, 71- 75

Diener, E., Sandvik, W., \& Pavot, R. (1991), Happinessis the frequency, not the intensity, of positive versus negative affect. In F. Strack, M. Argyle \& N. Schwarz (Ed) (1991). Subjective wellbeing: An interdisciplinary perspective, Pergamon, Oxford

Dubey, A. \& Agarwal, A. (2004). Feeling well inspite of chronic disease. Psychological Studies, 49(1), 63-68.

Fischer, M. H. (Feb 24, 2001). Dictionary of science quotation. Retrived from http://todayinsci.com/F/Fischer_Martin/FischerMartin-Quotations.htm

Gilman, R., \& Huebner, E. S. (2003). A review of life satisfaction research with children and adolescents. School Psychology Quarterly, 18, 192-205.

Hirsch, J.K., Britton, P.C., \& Conner, K.R. (2010). Psychometric Evaluation of the Life Orientation- Revised in treated opiate dependent individualsd. International Journal of Mental Health \& Addiction, 8(3), 423-431.

Horowitz, M., Adler, N., \& Kegeles, S. (1988). A scale for measuring the occurrence of Positive states of mind: A Preliminary report. Psychosomatic Medicine, 50, 477-483.

Huebner, S. E. (2004). Research on assessment of life satisfaction of children and adolescents. Social Indicators Research, 66, 3-33.

Lert, F., Chastang, J.F. \& Castano, I. (2001). Psychological stress among hospital doctors caring for HIV patients in the late nineties. AIDS Care, 13(6), 763-778.

Lyubomirsky S., King L. \& Diener E., (2005). The Benefits of Frequent Positive Affect: Does Happiness Lead to Success?, Psychological Bulletin, 131, 803-855.

Meier, L. L., Semmer, N. K., Elfering, A., \& Jacobshagen, N. (2008). The double meaning of control: Three-way interactions between internal resources, job control, and stressors at work. Journal of Occupational Health Psychology, 13, 244-258.

Mittal, D., \& Mathur, M. (2011). Positive forces of life and psychological well being among Corporate Professionals. Journal of Management \& Public Policy,3(1), 36-48.

Peterson, C., \& Bossio, L.M. (1991). Health and Optimism. New York: Free Press.

Ryan R. M., \& Deci E. L. (2000). Self-determination theory and the facilitation of intrinsic motivation, social development and wellbeing. American Psychologist, 55, 68-78.

Ryff C. D. (1989). Happiness is everything, or is it? Explorations on the meaning of psychological well-being.Journal of Personality and Social Psychology, 57, 10591081. doi:10.1037/0022-3514.57.6.1069 
Ryff, C.D., \& Singer B. (1998). The contours of positive human health. Psychological Inquiry, 9, 1-28.

Scheier, M. F., Carver, C. S., \& Bridges, M. W. (1994). Distinguishing optimism from neuroticism (and trait anxiety, self-mastery, and self-esteem): A re-evaluation of the Life Orientation Test. Journal of Personality and Social Psychology, 67, 1063-1078.

Scheier, M.F. \& Carver, C.S. (1992). Effects of optimism on psychological and physical wellbeing: Theoretical overview and empirical update. Special issue on cognitive perspectives in health psychology. Cognitive Therapy and Research, 16 (2), 201-228.

Seligman M. E. P. (2002). Authentic happiness: Using the new positive psychology to realize your potential for lasting fulfilment. New York, NY: Free Press

Seligman M. E. P. (2011). Flourish: A visionary new understanding of happiness and wellbeing. New York, NY: Simon \& Schuster.

Shadowfax, M.D. (Jan 21, 2013). Dealing with psychological stress of being a doctor. Retrievesd from http://www.kevinmd.com/blog/2013/01/dealing-psychological-stress-doctor.

Snyder, C. R., Lehman, K. A., Kluck, B., \& Monsson, Y. (2006). Hope for rehabilitation and vice versa. Rehabilitation Psychology, 51, 89-112.

Souri, H., \& Hejazi, E. (2014). The Relationship between Resilience and Psychological Wellbeing: The Mediating Role of Optimism. Health Psychology,15(55), 5-15. 